\title{
Interventions to improve patient safety in transitional care - a review of the evidence
}

\author{
Kristin laugaland ${ }^{\mathrm{a}}$, Karina aase ${ }^{\mathrm{b}}$ and Paul barach ${ }^{\mathrm{b}}$ \\ ${ }^{a}$ Forde Hospital, Norway \\ ${ }^{b}$ University of Stavanger, Department of Health Studies. Stavanger, Norway \\ ${ }^{b}$ Utrecht University Medical Center, Department of Anesthesia and Center for Patient Safety, Utrecht, \\ Netherlands
}

\begin{abstract}
When a patient's transition from the hospital to home is less than optimal, the repercussions can be far-reaching hospital readmission, adverse medical events, and even mortality. Elderly, especially frail older patients with complex health care problems appear to be a group particularly at risk for adverse events in general, and during transitions across health providers in particular. We undertook a systematic review to identify interventions designed to improve patient safety during transitional care of the elderly, with a particular focus on discharge interventions. We searched the literature for qualitative and quantitative studies on the subject published over the past ten years. The review revealed a set of potential intervention types aimed at the improvement of communication that contribute to safe transitional care. Intervention types included professionoriented interventions (e.g. education and training), organisational/culture interventions (e.g. transfer nurse, discharge protocol, discharge planning, medication reconciliation, standardized discharge letter, electronic tools), or patient and next of kin oriented interventions (e.g. patient awareness and empowerment, discharge support). Results strongly indicate that elderly discharged from hospital to the community will benefit from targeted interventions aimed to improve transfer across healthcare settings. Future interventions should take into account multi-component and multi-disciplinary interventions incorporating several single interventions combined.
\end{abstract}

Keywords: Transitional care, elderly, patient safety, adverse events, interventions

\section{Introduction}

Transitional care has been recognized as a high risk area for patients due to the growing evidence indicating a strong correlation between patient handovers and adverse events [1-3].Transitional care has been defined as a set of actions designed to ensure the coordination and continuity of health care as patients transfer between different levels of care within the same or other locations [4]. The main goal of transitional care is optimal patient care and safety [5]. Elderly, especially frail older patients with complex health care problems appear to be a group particularly at risk for adverse events ${ }^{*}$

\footnotetext{
${ }^{*}$ Corresponding author: Kristin Alstveit Laugaland. Email:kristin.a.laugaland@uis.no. Tel.no: 51834141 mob:98486261
}

in general, and during transitions across health providers in particular [6-7]. Elderly typically receive care from many providers and move frequently within and across health care settings [4] and has been defined as a research priority [8]. The type and incidence of adverse events reported in the literature relate to adverse drug events, procedure related events, diagnostic test follow-up errors, nosocomial infections and falls. Ineffective care processes, poor communication and deficient documentation represent the major risk factors associated with these adverse events [9]. The physical and mental health of elderly may deteriorate after discharge. They may experience changes in the treatment regimen, and discontinuities during their transitions. In addition many elders often have a limited support system [10]. Combined with poor general health this leaves 
the elderly at high risk for rehospitalization, morbidity and mortality after discharge. The tendency in today's health care systems is that patients are often discharged "quicker and sicker" which in turn challenges the health care team to adequately prepare and complete the discharge process (i.e., planning, support and follow-up). It is vital that healthcare providers have the proper information to act as representatives for the elderly patient. The pursuit of patient safety interventions within transitional care of frail elderly should thus ideally be designed to address the current risk factors.

\section{Aim}

This paper focuses upon interventions designed to improve patient safety within transitional care of the elderly. We focus on the effects of discharge interventions on patient safety, e.g adverse events confined to elderly patients $(>65)$ who have been discharged either home or to a nursing home from tertiary care hospitals. The paper seeks to identify and evaluate the effects of the interventions in terms of effectiveness and efficiency of care processes.

\section{Methods}

A systematic literature search was conducted by using the electronic databases: PubMed, Medline, Cinahl, Academic Search Elite, the Cochrane Database of Systemic Reviews and the controlled trials register and in addition we scanned the reference lists of selected articles (snowballing). The following search terms were used: "discharge planning", "patient care planning", "follow-up care", "transitional care", "handoff", and "clinical pathways", all concepts in combination with "patient safety" AND/OR "interventions" AND "elderly". The following journals' contents pages were searched electronically for relevant papers: Journal of clinical nursing, Social science and Medicine, Aging and society, Age and Aging, Social care in the community, International Journal of Integrated Care. The search included randomized studies, review articles and descriptive studies and was limited to English language articles in peerreviewed journals. The review concentrates on recent literature published between 2000 and 2010. The criteria for inclusion were intervention studies proposed to improve transitional care, and more specifically, hospital discharge. The sample subjects were older patients (over age of 65) with a medical condition (e.g., chronic disease or frail elderly). We excluded studies of patients with a surgical condition or a mental/psychiatric condition from the review. Studies were eligible for inclusion if they described or measured the effects of discharge interventions on adverse patient outcome (i.e. readmission rates, rehospitalization, adverse events, medical errors, delay in diagnosis or treatment, mortality, patient, family and carer satisfaction).

\section{Results}

A substantial literature regarding discharge arrangements for elderly patients from hospital to home exists. The initial literature search identified 569 publications of which 37 met the inclusion criteria: 12 were review [8,11-21] papers , 11 were randomized controlled trials (RCT) [22-32], and 10 were descriptive studies [33-42]. The review revealed several systematic reviews that assess the effects of supporting elderly discharge from hospital to home. On average at least one review paper has been published each year for the past ten years. The oldest article included data from 1966 and the most recent one from 2010. A majority of review papers included solely RCT studies and other comparative designs. Two reviews included both qualitative and quantitative designs, and one review included evidence of descriptive studies solely. Some of the reviews included studies in which interventions target mixed patient population, elders in general $(>65)$ while others were restricted to studies with a specific patient group, in particular patients with congestive heart failure. All the review articles differed to some extent in their objectives. Several reviews state that there exists uncertainty about the overall effectiveness of discharge arrangements. The metareview by Mistian and colleagues (2007) concludes that there is overall very limited evidence that discharge interventions are effective. Occasionally, significant results are achieved due to local factors that may not be generalizable. For instance, comprehensive discharge planning and interventions in patients with heart failure have been proven effective. However, even though significant effects overall are absent, several reviews provide evidence that discharge arrangements for the elderly population is of value and has beneficial effects on reducing readmission rates and drug related problems. Interventions which address family and educational components show promising results. There is evidence indicating that interventions should commence well before discharge to have the best preconditions for successful results. A common feature recognized by most reviews is that interventions combining discharge planning and discharge support tend to yield the greatest effects. In the review of primary trials and studies the literature addressed several interventions and revealed a set of potential intervention types aimed to improve safe transitional care (see table 1). 
Table 1

Interventions with positive outcomes

\begin{tabular}{|c|c|c|c|c|c|}
\hline $\begin{array}{l}\text { Author and } \\
\text { year }\end{array}$ & Design & Type of intervention & Sample & Outcome Measures & Main results \\
\hline $\begin{array}{l}\text { Naylor et al } \\
1999\end{array}$ & $\begin{array}{l}\text { Randomized } \\
\text { clinical trial }\end{array}$ & $\begin{array}{l}\text { Comprehensive } \\
\text { discharge planning and } \\
\text { home follow-up (at } \\
2,6,12,24 \text { weeks) } \\
\text { protocol designed for } \\
\text { elders at risk for poor } \\
\text { outcomes after } \\
\text { discharge and } \\
\text { implemented by } \\
\text { advanced practise } \\
\text { nurse }\end{array}$ & $\begin{array}{l}\text { A total of } 363 \\
\text { patients (age }>65) \\
186 \text { in the control } \\
\text { group and } 177 \text { in the } \\
\text { intervention group }\end{array}$ & $\begin{array}{l}\text { Readmission, time to } \\
\text { first readmission, } \\
\text { acute care visits after } \\
\text { discharge, cost, } \\
\text { functional status, } \\
\text { depression and patient } \\
\text { satisfaction }\end{array}$ & $\begin{array}{l}\text { An advanced practice nurse- } \\
\text { centered discharge planning } \\
\text { and home care intervention } \\
\text { for at-risk hospitalized elders } \\
\text { reduced readmissions, } \\
\text { lengthened the time between } \\
\text { discharge and readmission, } \\
\text { and decreased the costs of } \\
\text { providing health care. } \\
\text { However there were no } \\
\text { significant group differences } \\
\text { in postdischarge acute care } \\
\text { visits, functional status, } \\
\text { depression or patient } \\
\text { satisfaction. }\end{array}$ \\
\hline $\begin{array}{l}\text { Caplan et al } \\
2004\end{array}$ & $\begin{array}{l}\text { Prospective } \\
\text { randomized } \\
\text { controlled trial }\end{array}$ & $\begin{array}{l}\text { Comprehensive } \\
\text { geriatric assessment } \\
\text { (CGA) }\end{array}$ & $\begin{array}{l}\text { A total of } 575 \\
(\text { age }>75) \\
\text { (intervention } n=293 \text {; } \\
\text { control } n=282 \text { ) }\end{array}$ & $\begin{array}{l}\text { Primary; all } \\
\text { admissions to the } \\
\text { hospital within } 30 \\
\text { days of the initial ED } \\
\text { visit. Secondary: } \\
\text { Elective and } \\
\text { emergency } \\
\text { admissions, and } \\
\text { nursing home } \\
\text { admissions and } \\
\text { mortality. }\end{array}$ & $\begin{array}{l}\text { Intervention patients had a } \\
\text { lower rate of all admissions } \\
\text { to the hospital during the } \\
\text { first } 30 \text { days after the initial } \\
\text { ED visit }(16.5 \% \text { vs } \\
22.2 \% ; P=0.048) \text {, a lower } \\
\text { rate of emergency } \\
\text { admissions during the } 18- \\
\text { month follow-up ( } 44.4 \% \text { vs. } \\
54.3 \% P=0.007) \text {. There was } \\
\text { no difference in admission to } \\
\text { nursing homes or mortality. }\end{array}$ \\
\hline $\begin{array}{l}\text { Naylor et al } \\
2004\end{array}$ & $\begin{array}{l}\text { Randomized } \\
\text { controlled trial }\end{array}$ & $\begin{array}{l}\text { An advanced practice } \\
\text { nurse directed } \\
\text { discharge planning and } \\
\text { home follow up } \\
\text { (through } 52 \text { weeks } \\
\text { postindex hospital } \\
\text { discharge) protocol }\end{array}$ & $\begin{array}{l}\text { A total of } 239 \\
(\text { age }>65)(\text { control } n= \\
121 ; \text { intervention } \\
n=118)\end{array}$ & $\begin{array}{l}\text { Time to first } \\
\text { rehospitalisation or } \\
\text { death, number of } \\
\text { rehospitalizations, } \\
\text { quality of life, } \\
\text { functional status, cost } \\
\text { and satisfaction with } \\
\text { care. }\end{array}$ & $\begin{array}{l}\text { Time to first readmission or } \\
\text { death was longer in } \\
\text { intervention group patients. } \\
\text { At } 52 \text { weeks, intervention } \\
\text { group patients had fewer } \\
\text { readmissions and lower } \\
\text { mean total cost. However, } \\
\text { only short term } \\
\text { improvements were } \\
\text { demonstrated in the } \\
\text { intervention group } \\
\text { concerning overall quality of } \\
\text { life and patient satisfaction. }\end{array}$ \\
\hline $\begin{array}{l}\text { Anderson et } \\
\text { al } 2005\end{array}$ & $\begin{array}{l}\text { Randomized } \\
\text { controlled trial }\end{array}$ & $\begin{array}{l}\text { A comprehensive } \\
\text { community hospital- } \\
\text { based heart failure } \\
\text { program. (Discharge } \\
\text { planning and follow- } \\
\text { up). }\end{array}$ & $\begin{array}{l}\text { A total of } 121 \\
\text { patients (mean age } \\
78.5) \text { Intervention } n= \\
44: \\
\text { control } n=77 \text { ) }\end{array}$ & $\begin{array}{l}\text { Readmission rate and } \\
\text { utilization of home } \\
\text { health care services }\end{array}$ & $\begin{array}{l}\text { Intervention subjects had an } \\
11.4 \% \text { readmission rate } \\
\text { within } 6 \text { months, compared } \\
\text { with a } 44.2 \% \text { readmission } \\
\text { rates in control subjects. } \\
\text { There was a significant } \\
\text { increase in the number of } \\
\text { both skilled nurse visits and } \\
\text { home health aide visits } \\
\text { required in the control } \\
\text { group. }\end{array}$ \\
\hline $\begin{array}{l}\text { Sinclair et al } \\
2005\end{array}$ & $\begin{array}{l}\text { Randomized } \\
\text { controlled trial }\end{array}$ & $\begin{array}{l}\text { A single-blind } \\
\text { randomised controlled } \\
\text { trial comparing home- } \\
\text { based intervention by a } \\
\text { nurse with usual care } \\
\text { for patients with } \\
\text { cardiac problems }\end{array}$ & $\begin{array}{l}\text { A total of } 324 \\
\text { Patients (qge }>65) \\
\text { (intervention } n=163 \text {; } \\
\text { control group } \\
n=161) \text {. }\end{array}$ & $\begin{array}{l}\text { Deaths, hospital } \\
\text { readmissions and use } \\
\text { of outpatient services }\end{array}$ & $\begin{array}{l}\text { At } 100 \text { day follow-up there } \\
\text { was no difference in deaths, } \\
\text { activities of daily living or } \\
\text { overall quality of life, but } \\
\text { those in the intervention } \\
\text { group scored significantly } \\
\text { better on the confidence and } \\
\text { self-esteem subsections. The } \\
\text { intervention group had fewer } \\
\text { hospital readmissions }(35 \\
\text { versus } 51, \text { relative risk } 0.68 \text {, } \\
95 \% \text { CI } 0.47-0.98, P<0.05) \text {. }\end{array}$ \\
\hline $\begin{array}{l}\text { Coleman et } \\
\text { al } 2006\end{array}$ & $\begin{array}{l}\text { Randomized } \\
\text { controlled trial }\end{array}$ & $\begin{array}{l}\text { Care transition } \\
\text { intervention. } \\
\text { Intervention patients } \\
\text { received (1) tools to } \\
\text { promote cross - site } \\
\text { communication; (2) } \\
\text { encouragement to take }\end{array}$ & $\begin{array}{l}\text { A total of } 712 \\
\text { patients }(\text { age }>65) \\
\text { (intervention } n=360 \text {; } \\
\text { control } n=352 \text { ) }\end{array}$ & $\begin{array}{l}\text { Rates of } \\
\text { rehospitalisation at } \\
30,90 \text { and } 180 \text { days } \\
\text { after hospital } \\
\text { discharge }\end{array}$ & $\begin{array}{l}\text { Intervention patients had } \\
\text { lower rehospitalisation rates } \\
\text { at } 30 \text { days and at } 90 \text { days } \\
\text { than control subjects. The } \\
\text { mean hospital cost were } \\
\text { lower for intervention } \\
\text { patients vs control at } 180\end{array}$ \\
\hline
\end{tabular}




\begin{tabular}{|c|c|c|c|c|c|}
\hline & & $\begin{array}{l}\text { a more active role in } \\
\text { their care; and, ( } 3) \\
\text { continuity across } \\
\text { settings and guidance } \\
\text { from a "transition } \\
\text { coach" }\end{array}$ & & & days. \\
\hline $\begin{array}{l}\text { Schnipper et } \\
\text { al } 2006\end{array}$ & $\begin{array}{l}\text { Randomized } \\
\text { trial }\end{array}$ & $\begin{array}{l}\text { Patient counselling } \\
\text { and follow-up by } \\
\text { pharmacist }\end{array}$ & $\begin{array}{l}\text { A total of } 178 \\
\text { patients (mean age } \\
58.4)(\text { intervention } \\
n=92 ; \\
\text { control } n=84)\end{array}$ & $\begin{array}{l}\text { Rate of preventable } \\
\text { adverse drug events } \\
\text { (ADEs) }\end{array}$ & $\begin{array}{l}\text { Medication review, } \\
\text { discharge counselling and } \\
\text { telephone follow-up by } \\
\text { pharmacist were associated } \\
\text { with a significant lower rate } \\
\text { of preventable ADEs } 30 \\
\text { days after hospital discharge. } \\
\text { Preventable medication } \\
\text { related ED visits and } \\
\text { hospital readmissions were } \\
\text { similarly reduced. On the } \\
\text { other hand the groups did } \\
\text { not differ significantly with } \\
\text { respect to total ADEs, total } \\
\text { health care utilization, or } \\
\text { patient satisfaction. }\end{array}$ \\
\hline $\begin{array}{l}\text { Midlov et el } \\
2008 \text { a }\end{array}$ & $\begin{array}{l}\text { A prospective } \\
\text { intervention } \\
\text { with } \\
\text { retrospective } \\
\text { controls }\end{array}$ & $\begin{array}{l}\text { Use of medication } \\
\text { report at discharge }\end{array}$ & $\begin{array}{l}\text { A total of } 427 \\
\text { patients } \\
(\text { age }>65) \text { (intervention } \\
n=248 \text {; control group } \\
n=179)\end{array}$ & $\begin{array}{l}\text { Need for medical care } \\
\text { in hospital or primary } \\
\text { care within three } \\
\text { months after } \\
\text { discharge from } \\
\text { hospital. }\end{array}$ & $\begin{array}{l}\text { The use of medication report } \\
\text { reduced the need for medical } \\
\text { care due to medication } \\
\text { errors. Of the patients with } \\
\text { medication report } 11 \text { out of } \\
248(4.4 \%) \text { needed medical } \\
\text { care because of medication } \\
\text { errors compared with } 16 \text { out } \\
\text { of } 179(8,9) \text { of patients } \\
\text { without medication report. } \\
\text { The use of medication report } \\
\text { also reduced the need for } \\
\text { administrative corrections } \\
\text { due to medication errors. }\end{array}$ \\
\hline $\begin{array}{l}\text { Midlov et al } \\
2008 \text { b }\end{array}$ & $\begin{array}{l}\text { A prospective } \\
\text { intervention } \\
\text { with } \\
\text { retrospective } \\
\text { controls }\end{array}$ & $\begin{array}{l}\text { Use of medication } \\
\text { report at discharge } \\
\text { describing all } \\
\text { medication changes } \\
\text { during hospital stay } \\
\text { and the reason for } \\
\text { these changes }\end{array}$ & $\begin{array}{l}\text { A total of } 427 \\
\text { patients }(\text { age }>65 \text { ) } \\
\text { (intervention } n \\
=248 ; \text { control group } \\
n=179 \text { ) }\end{array}$ & $\begin{array}{l}\text { Number of } \\
\text { medication errors }\end{array}$ & $\begin{array}{l}79(32 \%) \text { patients in the } \\
\text { intervention group had at } \\
\text { least one medication error as } \\
\text { compared with } 118(66 \%) \\
\text { patients in the control group. } \\
\text { In the intervention group } 15 \\
\% \text { of the patients had errors } \\
\text { that were considered to have } \\
\text { moderate or high risk of } \\
\text { clinical consequences } \\
\text { compared with } 32 \% \text { in the } \\
\text { control group. }\end{array}$ \\
\hline $\begin{array}{l}\text { Courtney et } \\
\text { al } 2009\end{array}$ & $\begin{array}{l}\text { Randomized } \\
\text { controlled trial }\end{array}$ & $\begin{array}{l}\text { Comprehensive } \\
\text { nursing and } \\
\text { physiotherapy } \\
\text { assessment and } \\
\text { follow-up }\end{array}$ & $\begin{array}{l}\text { A total of } 128 \\
\text { patients (age }>65 \text { ) } \\
\text { (intervention } n= \\
64 ; \text { control } n=64 \text { ) }\end{array}$ & $\begin{array}{l}\text { Emergency health } \\
\text { service utilization and } \\
\text { high-related quality of } \\
\text { life } 4,12 \text { and } 24 \\
\text { weeks after discharge. }\end{array}$ & $\begin{array}{l}\text { The intervention group } \\
\text { required significantly fewer } \\
\text { emergency hospital } \\
\text { readmissions ( } 22 \% \text { of } \\
\text { intervention group vs } 47 \% \\
\text { of control group). The } \\
\text { intervention group reported } \\
\text { significantly greater } \\
\text { improvements in quality of } \\
\text { life than the control group. }\end{array}$ \\
\hline $\begin{array}{l}\text { Rytter et al } \\
2010\end{array}$ & $\begin{array}{l}\text { Randomized } \\
\text { controlled trial }\end{array}$ & $\begin{array}{l}\text { Follow-up program by } \\
\text { GPs and district } \\
\text { nurses. }\end{array}$ & $\begin{array}{l}\text { A total of } 331 \\
\text { patients } /(\text { age }>65) \\
\text { intervention } n= \\
166 ; \text { control } n=165)\end{array}$ & $\begin{array}{l}\text { Primary: Readmission } \\
\text { and any kind of } \\
\text { concordance between } \\
\text { the GPs knowledge of } \\
\text { the medical treatment } \\
\text { and what the patient } \\
\text { was actually taking. } \\
\text { Secondary: degree to } \\
\text { which the GP } \\
\text { implemented the } \\
\text { recommended follow- } \\
\text { up as described in the } \\
\text { hospital discharge } \\
\text { letter, cost, functional } \\
\text { ability, death rate, } \\
\text { patient satisfaction } \\
\text { and self rated health. }\end{array}$ & $\begin{array}{l}\text { Control group patients were } \\
\text { more likely to be readmitted } \\
\text { than intervention group } \\
\text { patients ( } 52 \% \text { vs } 40 \% \\
P=0.03 \text { ). In the intervention } \\
\text { group, the proportions of } \\
\text { patients who used prescribed } \\
\text { medication of which the GP } \\
\text { was unaware ( } 48 \% \text { vs } 34 \% \\
\text { and who did not take the } \\
\text { medication prescribed by the } \\
\text { GP ( } 39 \% \text { vs } 28 \% \text { ) were } \\
\text { smaller than in the control } \\
\text { group. }\end{array}$ \\
\hline
\end{tabular}


As several studies were identified, table 1 is limited to interventions that demonstrate positive effects on measures related to the prevention of adverse patient outcomes. These intervention types included profession-oriented interventions (e.g. education and training); organisational interventions (e.g. transfer nurse, transition coach, discharge protocol, discharge planning, discharge follow-up, medication reconciliation, standardized discharge letter, electronic tools); or patient-and next of kin- oriented interventions (e.g. patient empowerment, discharge support). The primary articles included in our review overlap somewhat with those cited by other review papers. Despite the variety of interventions reported in the literature, the review did not provide evidence for the validity of one intervention over others. However, some interventions have achieved good results and therefore deserve attention. The characteristics of these interventions are presented in table 2 . Supplementary comments for each are then given.

Table 2

Features of successful interventions

Features of successful interventions

$>$ Interventions that commence at an early stage and are maintained throughout hospitalization and the post-discharge period.

$>$ Interventions that consist of a key health care worker which acts as a discharge coordinator.

$>$ Interventions that include patient participation and /or education.

Interventions that involve family caregivers.

$>$ Interventions which undertake a multidisciplinary approach.

$>$ Curriculum interventions teaching transitional care

Pharmacy interventions- medication reconciliation.

$>$ Standardized medication reports.

$>$ Comprehensive transitional care programs with multiinterventional components.

\section{$>$ Discharge planning and support}

Two categories of discharge interventions, are divided in discharge preparation and discharge support [16]. A common feature in several studies is that combining hospital discharge preparation/planning (interventions that mainly take place during admission in the hospital) and discharge support (interventions that mainly take place after discharge from the hospital) for older patients provides significant results when compared with interventions provided in the hospital or community setting only. The effects, especially on readmission risk reduction appear most apparent in interventions provided in both care settings [22-24, 27]. However, it must be mentioned that Rytter and colleagues [32] among others [26] achieved positive but not significant effects based solely on discharge support including joint follow-up home visits involving both the general practitioner and the district nurse. Halasyamani and colleagues [37] highlight and emphasize the need for follow-up appointment within at most 2 weeks of discharge or sooner with patients with fragile clinical conditions.

\section{Key - coordinator}

Several intervention studies have designated a nurse, most frequently an advanced practice registered nurse as the intervention clinical manager or leader [21-22, 24]. Naylor and colleagues [21] identified in their review nine studies that reported a statistically positive effect on readmission. The common feature among these interventions was that they all relied on a nurse as the clinical leader or manager of care. Interventions that included a key liaison person, or discharge coordinator to organize information exchange and transfer had in addition to improving communication a positive impact on patient and caregiver satisfaction [12]. Payne and colleagues [12] stress that there is still insufficient research evidence to determine from which professional background this key-coordinator should come and whether they should be based in the hospital or community. Naylor and colleagues [22] successfully tested the effectiveness of a comprehensive advanced practice nurse (APN) centered discharge planning and follow-up intervention, designed for older people at risk for rehospitalization. The APN centered discharge intervention was found to reduce readmission, lengthen the time between discharge and readmission and decrease cost. The intervention included a comprehensive patient and caregiver assessment of knowledge, education, caregiver burden and resources and an individualized and documented discharge plan developed in collaboration with the caregiver, patient, physician and other health team members. The post discharge follow-up support in terms of home visits and telephone contact was also a part of the intervention. It is stressed that APNs involvement throughout the transition from hospital to home provided a safety net designed to prevent medication and other medical errors and assure accurate transfer of information. Naylor and colleagues [24] tested a similar APN directed intervention program to elder patients with heart failure, achieving even better results. The authors argued that the success was largely driven by two factors; (1) the continuity of care provided by the same APN who coordinated the patients discharge plan and implemented in the patients home; and, (2) the use of highly skilled APNs who are prepared to use a holistic approach to address the complex need of patients and their caregivers.

Patient and family involvement/Education

Compelling evidence supported by both qualitative $[34,41]$ and quantitative 
$(22,24,27)$ studies highlight the importance of involving patient and family care givers in the hospital discharge process. Numerous studies on discharge planning have identified the importance of the role of the family, suggesting it as one of the most significant factors influencing the success of discharge planning for frail older patients [43]. Studies indicate that patients express clear preference for participation [41] and that approximately $46 \%$ of families reported little or no involvement in discharge planning [33]. Evidence has shown that family caregivers who were included in discharge planning had significantly higher scores on satisfaction, feelings of preparedness and acceptance of the caregiver role [34]. Providing patients with educational sessions pre- and post- discharge have been found to have positive effects. Parker and colleagues [13] imply that educational programs/ interventions represent the single most positive effect of any single type of intervention, and stress that interventions which empower patients by paying particular attention to their specific educational needs should be of great interest to the field.

\section{Multidisciplinary approach}

A multidisciplinary approach to the provision of services for patients following discharge is viewed as a best practice [17]. Avlund and colleagues [44] demonstrate that elders discharged from medical wards most likely benefit from interdisciplinary home-visits following discharge. A multidisciplinary team approach is applied in several studies which report positive effects [2225,45]. All the health care professionals interviewed in the study by Bull and Roberts [34] identified a multi-disciplinary team approach as critical for a proper discharge because elders have complex needs and each discipline brought different perspectives in planning for the elders' needs following hospitalization. In addition the interdisciplinary team emphasized that members of the team learned from each other, valued each others' perspectives and came to trust the judgement of other team members.

Education and training
Historically there have been few
curricular/curriculum interventions teaching
transitional care to physicians. However, it has been
recognized that curricular interventions teaching
this topic to physicians in training and physicians
have increased dramatically over the past ten years
[46]. Study findings from an education intervention
[40] reveal that medical students transitional care
skills improved after the implementation of a
transition in care curriculum. In addition students
also rated the usefulness of such education above
all other project work in all required clerkships.
Another educational intervention conducted by

Ouchida and colleagues [39] reported similar significant results using a pre and post test design. This multi-modal educational intervention for medical students increased their transitional care knowledge. After the intervention $56 \%$ (vs 14.9\%) identified medication errors as the most common source of adverse events after discharge. Significantly more participants reported feeling competent or expert in safely discharging chronically ill patients $(66.3 \%$ vs. $9.8 \%)$ and in educating patients about discharge medications. Participants also reported changes in transitional care behaviours after educational interventions to ensure safe transitions [39]. It is an imperative to implement interventions that teach physicians and nurses to recognize their role within the interdisciplinary team and their responsibility to ensure safe transitions at an early stage of clinical training [4].

\section{$>$ Pharmacy interventions / medication reconciliation}

It is widely known that older age and polypharmacy are risk factors for medication discrepancies and errors [47-48].It is also widely known that medication discrepancies occur commonly during hospital discharge. All the studies included in the review by Garcia-Caballos and colleagues [19] underscored the high frequency and complexity of drug related problems in elderly patients after hospital discharge. Several studies test the impact of pharmacist interventions at discharge aimed to prevent and reduce adverse drug events following discharge. Studies indicate that pharmacists may play an important role in preventing prescribing errors or medical related problems [28,49,50] Schnipper and colleagues [28] showed that medication review, discharge counseling and telephone follow-up by a pharmacist were associated with a significant lower rate of preventable adverse drug events 30 days after hospital discharge. The same study also revealed that the medical team often misunderstood the patients' preadmission medication regimen and carried these inaccuracies to the discharge medication orders. Similar findings have been identified by Glintborg and colleagues [38] revealing that the hospital had insufficient knowledge of prescriptions and that they only reported half of the administered drugs in the discharge letter. The use of a pharmacist transition coordinator improved aspects of inappropriate use of medicines across health sectors [28, 50-51]. Pharmacist review of medication list may help identify omitted or indicated medications on transfer [8]. We also found studies that question the benefit of such interventions [52]. However, the studies included in the review by Hanlon and colleagues [14] provided considerable evidence that clinical pharmacy interventions reduced the occurence of drug related problems for elderly, 
including improvements in medication adherence and suboptimal prescribing. There was limited evidence that such interventions reduce morbidity, mortality or health care costs. Medication reconciliation includes the collection of a complete medication list from the patient at the point of entry; using that information when prescribing medications; and, comparing the new medication orders against the original medication list to ensure that all the correct medications are ordered or held as appropriate [53].

\section{$>$ Standardized medication reports/discharge} summary

The use of standardized medication reports at discharge have also been proven beneficial. Midlov and colleagues [30] conduced an intervention study to assess the effects on medication errors when elderly patients are transferred from the hospital to primary care by use of a structured medication report. In contrast to the regular information exchange this report also described all medication changes during hospital stay and the reasons for these changes. The study demonstrated that the use of the developed structured medication report reduced the number of medication errors by more than 50\%. Midlov and colleagues [29] also tested if the same medication report could reduce the number of patients with clinical outcomes due to medication errors. They concluded that the medication report appears to represent an effective tool to decrease adverse clinical consequences when elderly patients are discharged from the hospital. Several studies have proposed standardized summaries or checklist for elderly patients in order to improve information transfer [37,54]. However, present information on the implementation or evaluation of these summaries or checklists is lacking.

> Comprehensive transitional care programs The studies conducted by Naylor and colleagues $[22,24]$ and Coleman and colleagues [27], focus on long term effects on rehospitalization. All studies are distinguished by the use of comprehensive transitional care programs which undertake a multiinterventional component approach. These comprehensive interventional care programs address several primary factors (highlighted in table 1) that are considered significant for successful discharge. Coleman and colleagues [27] reported significant reduction in readmission at 180 days post discharge compared to the control group. Similarly, Naylor and colleagues [22] achieved significant reduction in readmission rates at 24weeks post-discharge. Naylor and colleagues argue that comprehensive transitional care programs have not been adopted due to lack of Medicare reimbursement, absence of marketing forces, and the challenges such care present to the culture of current practice. These challenges are characterized by the organization of care in distinct and separate silos, and limited longitudinal integration of physician and nursing care to support patients' needs.

\section{Discussion}

Elderly patients benefit from targeted interventions aimed at facilitating cross site communication and accurate information transfer in transitional care. Some studies report intervention effects related to decrease in adverse drug events and readmission rates, and an increase in patient and family satisfaction. Others demonstrate effects on cost effectiveness. Strong evidence of effectiveness seems principally to be limited to specific diagnostic groups managed in specific settings. This may suggest that developing a single approach within transitional care of the elderly is not possible because of the diversity and complexity of elderly health care [55]. This confirms that one-size fits all approaches to transitional care may not be sufficient [56]. Improving safe transitional care of the elderly will require future interventions that involve a multicomponent approach which incorporates and takes into account the characteristics presented in table 2 . We encourage that future interventions must focus in particular on comprehensive discharge planning combined with follow-up care. Interventions must incorporate patient participation and family involvement to a greater extent, where one must consider and take into account their preferences, goal settings, and an individualized care plan.

Educational efforts that strengthen patient selfmanagement have been proven effective. Though the family is often the first line of defense against problems within transitional care, little work has been done that focuses on building partnerships between patients, families and healthcare providers [57]. Poor communication between patients, family and health professionals, including deficient documentation is one of the primary obstacles to improving the patient discharge process [18]. There is a need for further investigation into the experiences and needs of older people and their families at home following hospitalization [17]. Interventions should further be based on effective multidisciplinary teamwork both within the hospital and between the hospital and the community. This teamwork should be based on clear and explicit core competencies [58].

This review reveals that interventions often focus on single groups such as nurses, physicians, patients or families, social workers, or occupational therapists. To our knowledge few studies undertake a multidisciplinary approach which involves multiple stakeholders. An interesting and somewhat surprising finding also recognized by Shepperd and colleagues [20] in their review is the fact that there 
are limited studies that involve secondary care settings in discharge planning. In the pursuit of patient safety, models that provide interventions across the hospital -community interface seem essential. Elders often have complex health care needs and each discipline may bring and fulfill different perspectives in planning for the elders' needs following hospitalization. We argue that it is vital to undertake a multidisciplinary approach if the objective is to improve transitional care of the elderly. We also highlight the need to increase the awareness of healthcare providers to the challenges of transitional care and make discharge planning a priority. Both nurses and physicians need formal training in transitional care as a core competency for caring for the elderly population [4]. Content in training and education must reflect skills that are necessary to promote cross-site collaboration (e.g. medication reconciliation and provider- provider communication). Lack of knowledge, experience and ability were all sited as important concerns related to discharge planning effectiveness in the study conducted by Bowles and colleagues [59]. Learning to work effectively in multidisciplinary teams should become an essential component of nursing and medicine education [33, 60].

Last we emphasize that simple tools have been proven effective, such as the use of structured medication reports at discharge, read back checklists, pharmacy interventions, and discharge support and follow-up in primary care. Single interventions appear to achieve short term effects as opposed to multi-component interventions which seem to achieve sustained long term effects especially in regards to reducing rehospitalization and health care utilization.

\section{Limitations}

A major weakness in this review is the absence of a thorough assessment of the methodological quality of the included studies. We emphazise that the studies are not bias-free, indicating the need for caution when interpreting the results. Several methodological problems limit the interpretation of findings. Ministian [16] stresses that "summing up bias generally results in more bias". However with this in mind, methodological issues have been taken into account in the framing of the conclusions. Most randomized controlled trials stated that control patients received "usual care". However, the authors seldom described what constituted "usual care". The intervention studies also varied considerably in measured outcomes, although a majority used readmission rates to identity poor transitional care. However, there is evidence that this outcome measure has limited value as an indicator of quality of care process in general [61].The sample size in the primary studies also varied in range, from 96 to 712 subjects. Overall, there is lack of large-scale empirical research in this field. Strategies to improve transitional care are insufficient and not sustained [8, 62-63]. Further research is therefore necessary to develop operationalized definitions for safe transitional care.

\section{Conclusions}

The study results presented in the paper indicate that elderly discharged from hospital to the community will benefit from targeted interventions aimed to improve transfer across healthcare settings and health care providers. Successful interventions have been proven to reduce readmission rates, adverse drug events, health care utilization, increased patient, family satisfaction and decreased cost. The characteristics of these successful interventions have been identified and highlighted in this review. Future interventions should take into account multi-component and multi-disciplinary interventions incorporating several single interventions combined. Finally, an important step is to introduce and highlight transitional care knowledge in curriculums for both nurses and physicians in addition to multidisciplinary training at an early stage of their education.

\section{References}

[1] A.J. Foster, H.J Murff, J.F Peterson et al, The incidence and severity of adverse events affecting patients after discharge from the hospital. Ann Intern Med (2003) 138:161-167.

[2] A.J. Foster, H.D Clark, A. Menard et al, Adverse events among medical patients after discharge from hospital. CMAJ (2004)

[3] C. Moore, J. Wisnivesky, S. Williams et al, Medical errors related to discontinuity of care from an inpatient to an outpatient setting. Journal of General Internal Medicine (2003), 18.

[4] E.A Coleman and C. Boult, Improving the quality of transitional care for persons with complex care needs. J Am Geriatr Soc (2003) 51:4, 556-7.

[5] S. Boutilier, Leaving critical care. Dimensions of critical care nursing (2007) 26:4

[6] E.A Coleman, Falling through the Cracks: Challenges and opportunities for Improving Transitional Care for Persons with Complex Care Needs. Journal of the American Geriatric Society (2003) 51:4, 549-55.

[7] M. Naylor and S.A Keating, Transitional care. American Journal of Nursing (2008) 108:9.

[8] M.A LaMantia, L.P Scheunemann, A. Viera, et al, Interventions to improve transitional care between nursing homes and hospitals: A Systematic Review. JAGS (2010) 58.

[9] K. Laugaland, K. Aase, P. Barach, Addressing Risk Factors for Transitional Care of the Elderly - Literature review. Healthcare Systems Ergonomics and Patient Safety. Taylor \& Francis Group (2011) 1183-191.

[10]D. Tsilimingras and D.W Bates, Addressing postdischarge adverse events: A neglected area. The Joint Commission Journal on quality and Patient Safety (2008) 34: 2.

[11]C.J Hyde, I.E Robert, A.J Sinclair A, The effects of supporting discharge from hospital to home in older people. Age and Aging (2000) 29.

[12] S. Payne, C. Kerr, S. Hawker et al, The communication of information about older people between health and social care practitioners. Age and Aging (2002) 31. 
[13] S.G. Parker, S.M Peet, A. McPherson, A.M Cannaby et al, A systematic review of discharge arrangements for older people. Health Technology Assessment (2002) 6, 4 .

[14]J.T Hanlon, C.I Lindblad, S.L Gray, Can clinical pharmacy services have a positive impact on drug-related problems and health outcomes in community-based older adults. The American Journal of Geriatric Pharmacotherapy (2003)2,1.

[15]C.O Phillips, S.M Wright, D.E Kern, et al, Comprehensive Discharge Planning With Postdischarge Support for Older Patients With Congestive Heart Failure. JAMA (2004) 291,11 .

[16]P. Mistiaen, A.L Francke, E. Poot, Interventions aimed at reducing problems in adult patients discharged from hospital to home: a systemic meta-review. BMC Health Services Research (2007) 7, 47.

[17]A. Coffey, Discharge older people from hospital to home: what do we know? International Journal of Older People Nursing (2006) 1.

[18] M. Bauer, L. Fitzgerald, E. Haesler, M. Manfrin, Hospital discharge for frail older people and their family. Are we delivering best practice? A review of the evidence. Journal of clinical Nursing (2009)18, 2539-2546.

[19] M. Garcia- Caballos, F. Ramos-Diaz, J.J Jimenez-Moleon, A. Bueno-Cavanillas, Drug- related problems in older people after hospital discharge and interventions to reduce them. Age and Aging (2010) 39, 430-438.

[20]S. Shepperd, J. McClaran, C.O Phillips, et al, Discharge planning from hospital to home (Review). The Cochrane Library (2010) Issue 1.

[21] M.D Naylor, E.T Kurtzman, D.M Olds, K.B Hirschman, The importance of transitional care in achieving health reform. Health Aff (2011) 30, 4: 746-54.

[22] M.D Naylor, D. Brooten, R Campbell, et al, Comprehensive Discharge Planning and Home Follow-up of Hospitalized Elders. JAMA (1999)281, 23.

[23]A.G Caplan, A.J Williams, B. Daly, K. Abraham, A Randomized, Controlled Trial of Comprehensive Geriatric Assessment and Multidisciplinary Intervention After Discharge of elderly from The Emergency Department -The DEED 11 Study. JAGS (2004) 52, 1417-1423.

[24] M.D Naylor, D. Brooten, R.L Campbell, et al, Transitional Care of Older Adults Hospitalized with Heart Failure: A Randomized controlled Trial. JAGS (2004) 52, 5.

[25]C. Anderson, B.V Deepak, Y. Amoateng-Adjepong, S. Zarich, Benefits of Comprehensive inpatient Education and Discharge Planning combined With Outpatient Support in Elderly Patients with Congestive Heart Failure. Congestive Heart Failure (2005) 11, 6: 315-321.

[26]A.J Sinclair, S.P Conroy, M. Davies, A.J Bayer, Postdischarge home-based support for older cardiac patients: a randomized controlled trial. Age and Aging (2005)43,338343.

[27]E.A Coleman, C. Parry, S. Chalmers, S.J Min, The Care Transitions Intervention. Arch Intern Med (2006) 166,18221828.

[28] J.L Schnipper, J.L Kirwin, M.C Cotugno, et al, Role of a pharmacist Counseling in preventing Adverse Drug Events After Hospitalization. Arch Intern Med (2006)166.

[29]P. Midlov, E Deierborg, L. Holmdahl, et al, Clinical outcomes from the use of Medication Report when elderly patients are discharged from hospital. Pharm World Sci (2008a) 30, 840-845.

[30] P. Midlov, L. Holmdahl, T. Eriksson et al, Medication report reduces number of medication errors when elderly patients are discharged from hospital. Pharm World Sci (2008b)30, 92-98.

[31] M. Courtney, H. Edwards, A. Chang et al, Fewer emergency readmissions and better quality of life for older adults at risk for hospital readmission: a randomized controlled trial to determine the effectiveness of a 24-week exercise and telephone follow-up program. J Am Geriatr Soc (2009) 57, 3:395-402.

[32]L. Rytter, H.N Jakobsen, F. Rønholt et al, Comprehensive discharge follow-up in patients ' homes by GPs and district nurses of elderly patients. Scandinavian Journal of Primary Health Care (2010) 28,146-153.
[33] M.J Bull, H.E Hansen, C.R Gross, Differences in Family Caregiver Outcomes by Their Level of Involvement in Discharge planning. Applied Nursing Research (2000)13, 2.

[34] M.J Bull and J. Roberts, Components of a proper hospital discharge for elders. Journal of Advanced Nursing (2001) $35,4: 571-581$.

[35] K.H Bowles, J.B Foust, M.D Naylor, Hospital Discharge Referral Decision Making: A Multidisciplinary Perspective. Applied Nursing Research (2003) 16, 3:134-143.

[36] R. Hellesø, L. Sorensen, M. Lorensen, Nurse`s information management at patients discharge from hospital to home. International journal of integrated care (2005) 5 .

[37] L. Halasyamani, S. Kripalani, E. Coleman, J. Schnipper et al, Transition of care for Hospitalized Elderly Patients Development of a Discahrge Checklist for Hospitalists. Journal of Hospital Medicine (2007) 1,6.

[38]B. Glintborg, S.E Andersen, K. Dalhoff, Insufficient communication about medication use at the interface between hospital and primary care. Qual Saf Helath Care (2007)16, 34-39

[39] K. Ouchida, M.V LoFaso, C. F Capello et al, Fast Forward Rounds: An Effective Method for Teaching Medical Students to Transition Patients Safely Across Care Settings. JAGS (2009) 57, 910-917.

[40] S. Bray-Hall, K. Schmidt, E. Aagaard, Towards Safe Hospital Discharge: A transition in care Curriculum for Medical Students. J Gen Intern Med (2010) 25, 8: 878-81.

[41]C. Foss C and D. Høfoss, Elderly persons experiences of participation in hospital discharge process. Patient Education and Counseling (2010)

[42] K. Ornstein K, K.L Smith, D. H Foer et al, To the Hospital and Back Home Again: A Nurse Practitioner- Based Transtional Care Program for Hospitalized Homebound People. JAGS (2011)59,3.

[43] V. Goodwin and B. Happell, Conflicting agendas between consumers and carers: the perspective of carers and nurses. International Journal of Mental Health Nursing (2006) 53, 646-655.

[44]K. Avlund, E. Jepsen, M. Vass, H. Lundemark, Effects of Comprehensive Follow-up Home Visits after Hospitalization on Functional Ability and readmission among Old Patients. A Randomized Controlled Study. Scandinavian Journal of Occupational Therapy (2002) 9, 1722.

[45]L.A Blewett, K. Johnson, T. McCarty, Improving geriatric transitional care trough inter-professional care teams. Journal of Evaluation in Clinical Practice (2010) 16, 57-63.

[46]I.M Buchanan and R.W Besdine, A Systematic review of curricular interventions in teaching transitional care to physicians in training and physicians. Academic Medicine (2011) 86, 5 .

[47]E.A Coleman, J.D Smith, D. Raha et al, Posthospital medication discrepancies: prevalence and contributing factors. Arsh Intern Med (2005) 165, 1842-7.

[48] K.M Gleason, M.R McDaniel, J. Feinglass et al, Result of the Medications At Transitions and Clinical Handoffs (MATCH) Study: An Analysis of Medication Reconciliation Errors and Risk Factors at Hospital Admission. J Gen Intern Med (2010) 25, 5:441-7.

[49]P.C Walker, S.J Bernstein, J.N Tucker Jones et al, Impact of a pharmacist-Facilitated Hospital Discharge Program. Arch Intern Med (2009) 169, 21.

[50]M. Crotty, D. Rowett, L. Spurling et al, Does the addition of a pharmacist transition coordinator improve evidencebased medication management and health outcomes in older adults moving from the hospital to a long-term care facility? Results from a randomized, controlled trial. Am J Geriatr Pharmacother (2004) 2,4.

[51]D.H Adel Quader, L. Harper, J.A Cantrill, M.P Tully, Pharmacists`s interventions in prescribing errors at hospital discharge. Drug saf (2010) 33, 11.

[52]I. Nazareth, A. Burton, S. Shulman et al, A pharmacy discharge plan for hospitalized elderly patients - a randomized controlled trial. Age and Aging (2001) 30, 3340. 
[53]S. Paparella and H. Pa, Medication Reconciliation: Doing What's Right for Safe Patient Care. J Emerg Nurs (2006) 32 .

[54] M.J Kergoat, J. Latour, I. Julin et al, A discharge summary adapted to the frail elderly to ensure transfer of relevant information from the hospital to community settings: a model. Geriatrics (2010)10,6

[55]K.J Johnson and P. Barach, Patient care handovers: what will it take to ensure quality and safety during times of transition? MJA (2009) 190, 11.

[56]H. Brown-Williams, L. Neuhauser et al, From hospital to home: Improving transitional care for older adults. Health Research for Action: University of California, Berkley, California (2006)

[57]L.L Popejoy, K. Moylan, C. Galambos, A Review of Discharge Planning Research of Older Adults 1990-2008). Western Journal of Nursing Research (2009) 31, 7.

[58]C. Baker, J. Battles, H. King, et al, The Role of Teamwork in the Professional Education of Physicians: Current Status and Assessment Recommendations. Joint Commission Journal on Quality and Safety (2005) 31,4: 185-202.
[59] K.H Bowles, J.B Foust, M.D Naylor, Hospital Discharge Referral Decisions Making: A Multidisciplinary Perspective. Applied Nursing Research (2003) 16:3.

[60]D. Baker, E. Salas, P. Barach et al, The Relation between Teamwork and Patient Safety. Handbook of Human Factors and Ergonomics in Health Care and Patient Safety, Carayon (Ed.). Lawrence Erlbaum Associates (2006) pp, 259-271.

[61]J. Benbassat and M. Taragin, Hospital readmissions as a measure of quality of health care. Arch Internal medicine (2000) 160:1074-81.

[62]T. Manser and S. Foster, Effective handover communication: An overview of research and improvement efforts. Best Practice \& Research Clinical Anaesthesiology (2011) 25:181-191.

63]E.S Patterson and R.L Wears, Patient Handoffs: Standardized and Reliable Measurement Tools Remain Elusive. Journal on Quality and Patient Safety (2010) 36:2. 